Supplement of Atmos. Chem. Phys., 20, 203-222, 2020

https://doi.org/10.5194/acp-20-203-2020-supplement

(C) Author(s) 2020. This work is distributed under

the Creative Commons Attribution 4.0 License.

(c) (i)

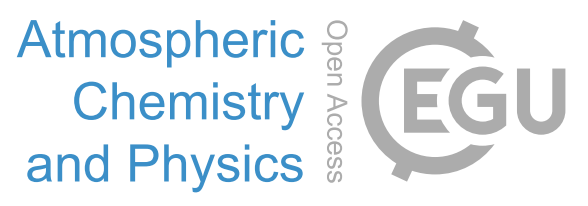

Supplement of

\title{
Local and synoptic meteorological influences on daily variability in sum- mertime surface ozone in eastern China
}

\section{Han Han et al.}

Correspondence to: Jane Liu (janejj.liu@ utoronto.ca)

The copyright of individual parts of the supplement might differ from the CC BY 4.0 License. 
Table S1. Mean absolute error (MAE), root mean square error (RMSE), and correlation coefficient $(r)$ of averaged ozone anomalies under each of the SWPs between observations and cross-validated predictions using MLR.

\begin{tabular}{|c|c|c|c|c|c|c|}
\hline & $\begin{array}{c}\text { P1: } \\
\text { PSW }\end{array}$ & $\begin{array}{l}\text { P2: } \\
\text { PS }\end{array}$ & $\begin{array}{c}\text { P3: } \\
\text { PNECV }\end{array}$ & $\begin{array}{c}\text { P4: } \\
\text { PWC }\end{array}$ & $\begin{array}{c}\text { P5: } \\
\text { PSWPSH }\end{array}$ & $\begin{array}{l}\text { P6: } \\
\text { PTC }\end{array}$ \\
\hline $\begin{array}{c}\text { MAE } \\
\left(\mu \mathrm{g} \mathrm{m}^{-3}\right)\end{array}$ & 1.0 & 1.1 & 1.6 & 1.7 & 1.6 & 2.2 \\
\hline $\begin{array}{c}\text { RMSE } \\
\left(\mu \mathrm{g} \mathrm{m}^{-3}\right)\end{array}$ & 1.4 & 1.4 & 2.0 & 2.2 & 2.1 & 2.8 \\
\hline$r$ & 0.97 & 0.75 & 0.81 & 0.93 & 0.78 & 0.94 \\
\hline
\end{tabular}


(a) $\mathrm{RH} 2 \mathrm{~m}$

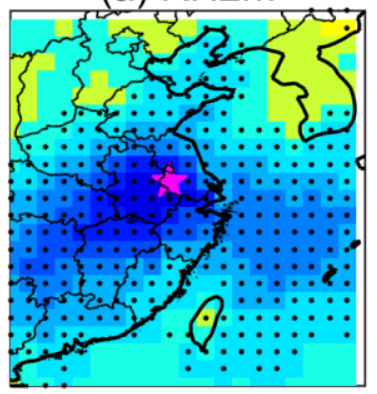

(e) U850

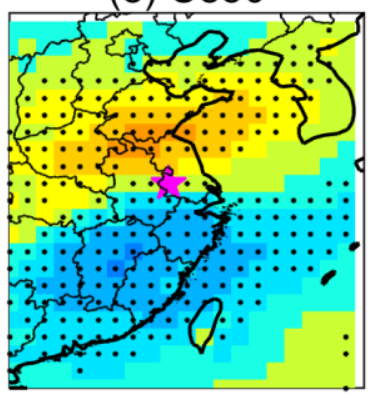

(i) HGT850

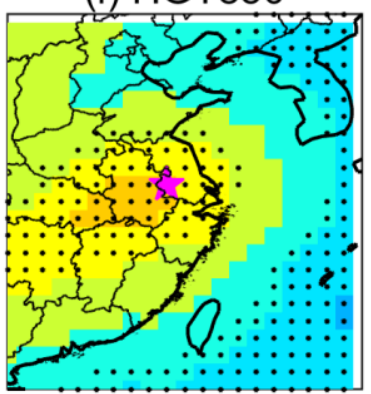

(b) CF

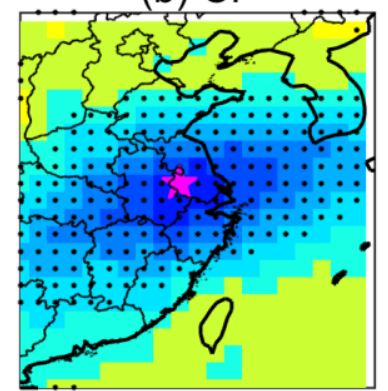

(f) $\mathrm{V} 850$

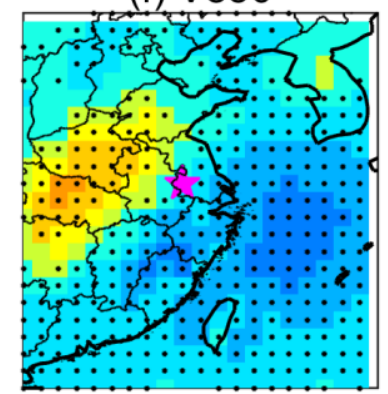

(j) SLP

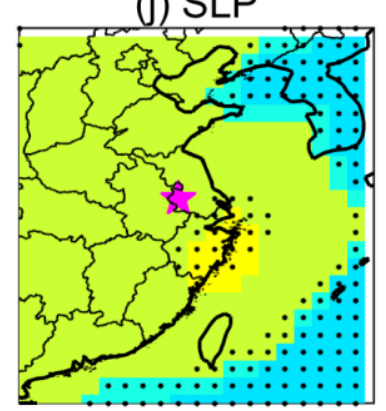

(c) $T 2 m$

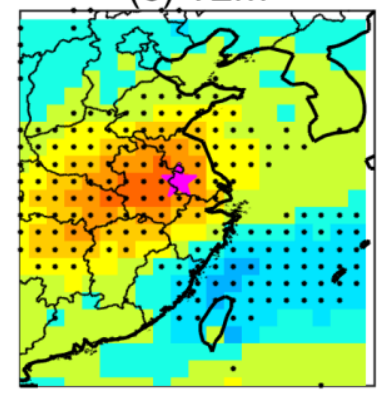

(g) W850

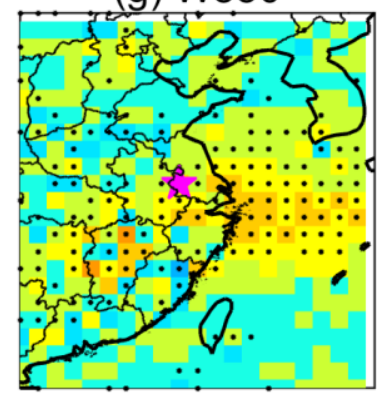

(d) PBLH

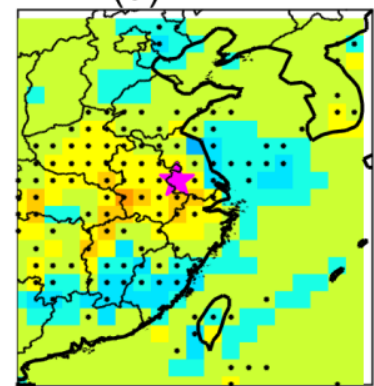

(h) WS850

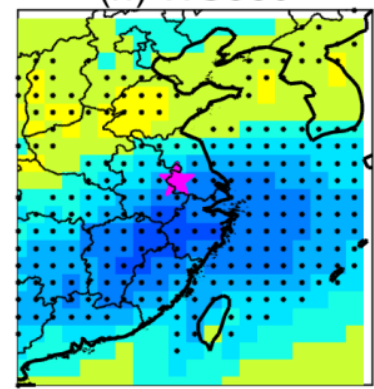

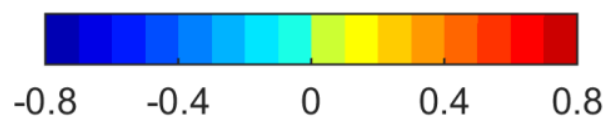

Figure S1. Correlation coefficients $(r)$ between daily surface ozone in the grid of Nanjing (purple pentagram) and each of the meteorological variables in all the grids over eastern China in summer during 2013-2018. The black dot in a grid indicates that the $r$ in that grid is significant $(\mathrm{p}<0.05)$. The abbreviations are for relative humidity at $2 \mathrm{~m}(\mathrm{RH} 2 \mathrm{~m})$, cloud fraction $(\mathrm{CF})$, temperature at $2 \mathrm{~m}(\mathrm{~T} 2 \mathrm{~m})$, planetary boundary layer height (PBLH), zonal wind at $850 \mathrm{hPa}(\mathrm{U} 850)$, meridional wind at $850 \mathrm{hPa}$ (V850), vertical wind at $850 \mathrm{hPa}$ (W850), wind speed at $850 \mathrm{hPa}$ (WS850), geopotential height at $850 \mathrm{hPa}$ (HGT850), and sea level pressure (SLP). 
(a) Mode 1, spatial weight
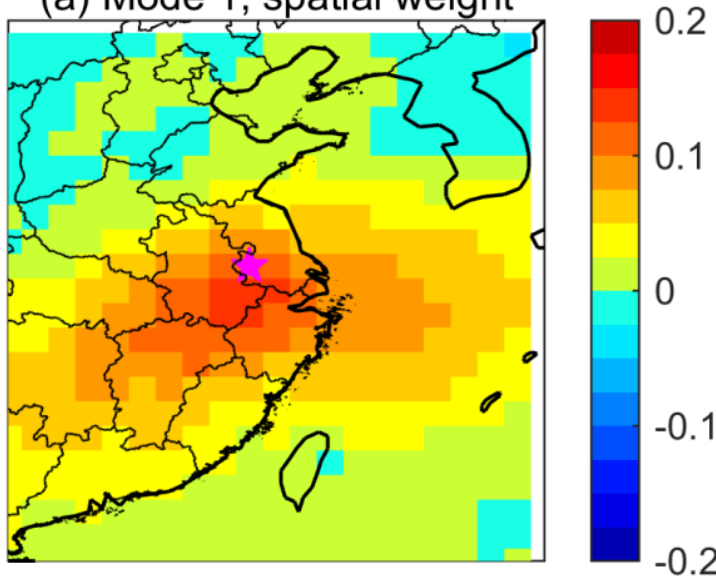

(c) Mode 2, spatial weight

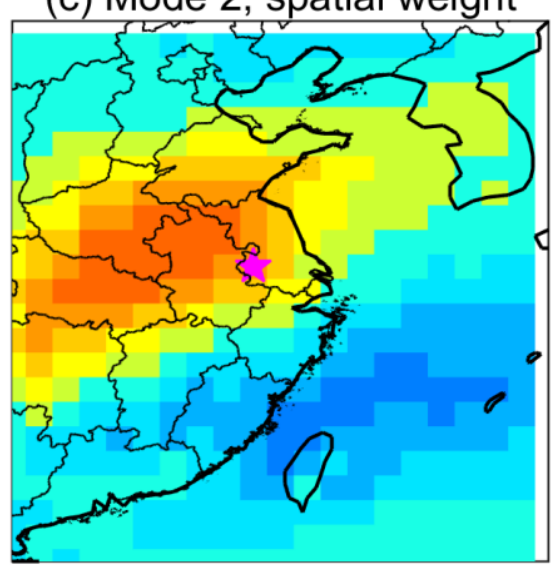

0.2

0.1

0
WS850

HGT850

SLP

(b) Mode 1, variable weight
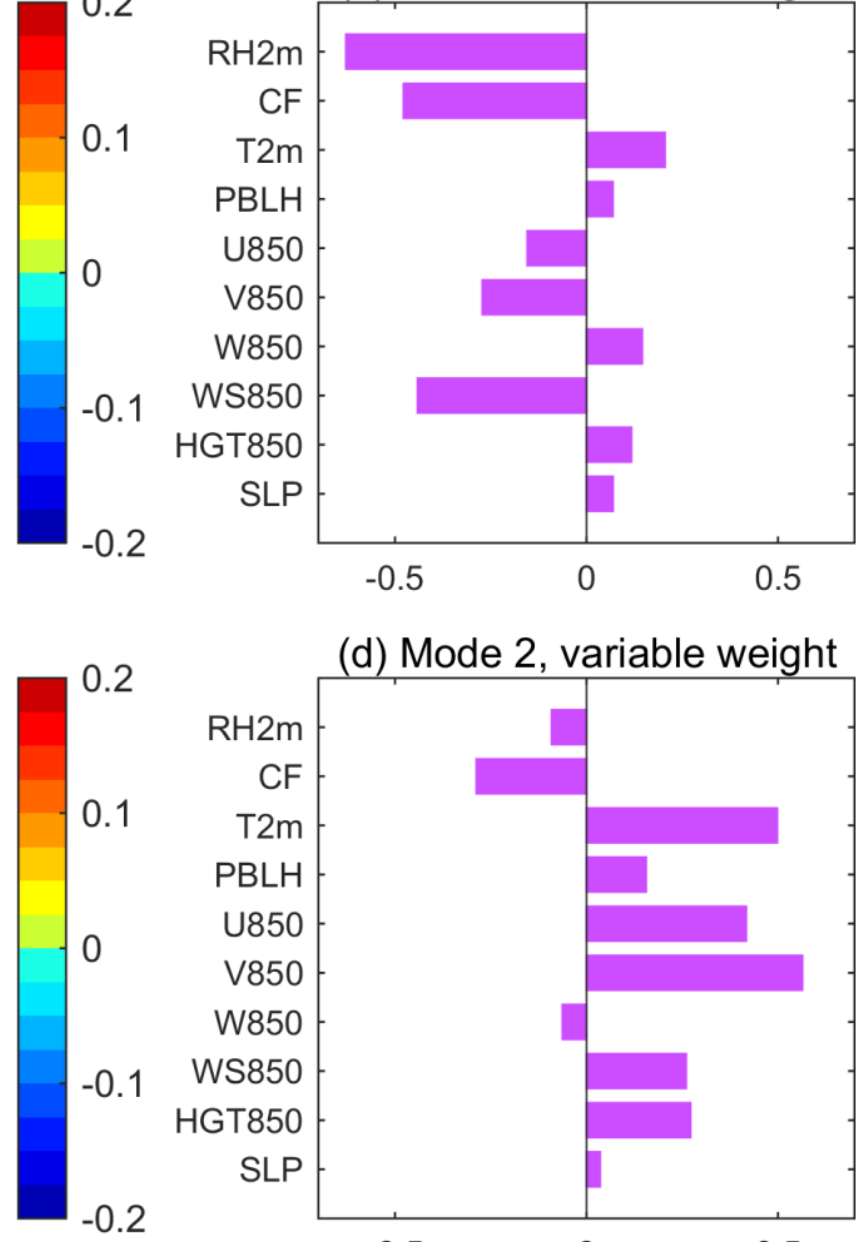

(d) Mode 2, variable weight

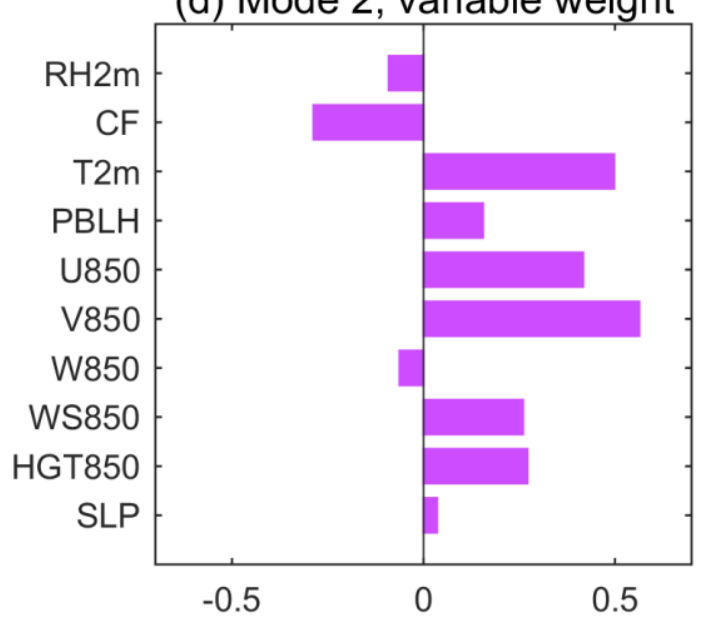

Figure S2. Spatial and variable weights of the first (a, b) and second (c, d) singular value decomposition (SVD) modes describing the spatial correlations of surface ozone in the grid of Nanjing (purple pentagram) and ten meteorological variables in all the grids over eastern China in summer during 2013-2018. The first and the second SVD modes, respectively, explain $58 \%$ and $22 \%$ of the total variance. The ten meteorological variables are relative humidity at $2 \mathrm{~m}(\mathrm{RH} 2 \mathrm{~m})$, cloud fraction $(\mathrm{CF})$, temperature at $2 \mathrm{~m}(\mathrm{~T} 2 \mathrm{~m})$, planetary boundary layer height $(\mathrm{PBLH})$, zonal wind at $850 \mathrm{hPa}$ (U850), meridional wind at $850 \mathrm{hPa}$ (V850), vertical wind at $850 \mathrm{hPa}$ (W850), wind speed at $850 \mathrm{hPa}$ (WS850), geopotential height at $850 \mathrm{hPa}$ (HGT850), and sea level pressure (SLP). 


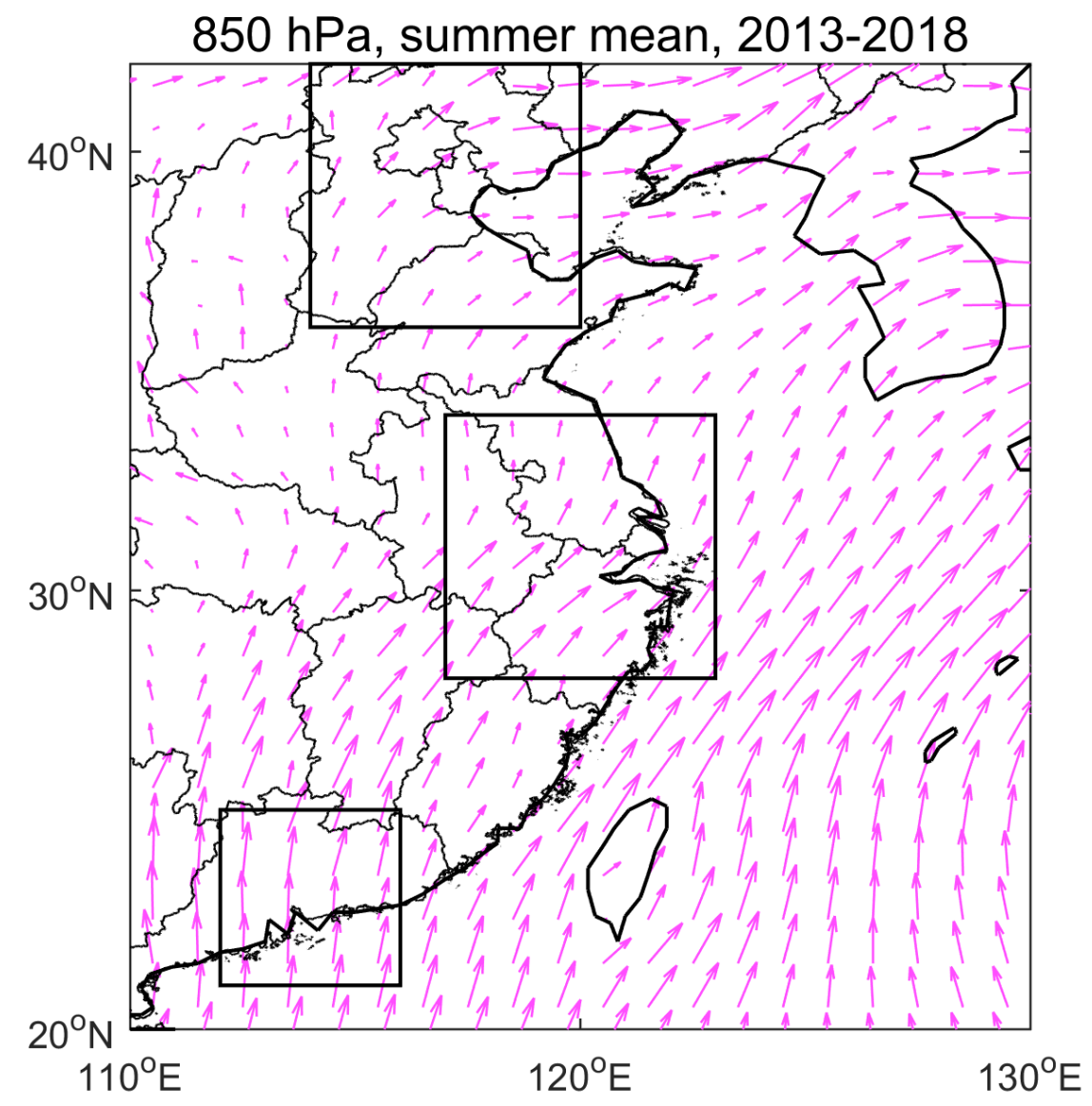

Figure S3. Summer mean wind field at $850 \mathrm{hPa}$ in eastern China averaged over 2013-2018. 

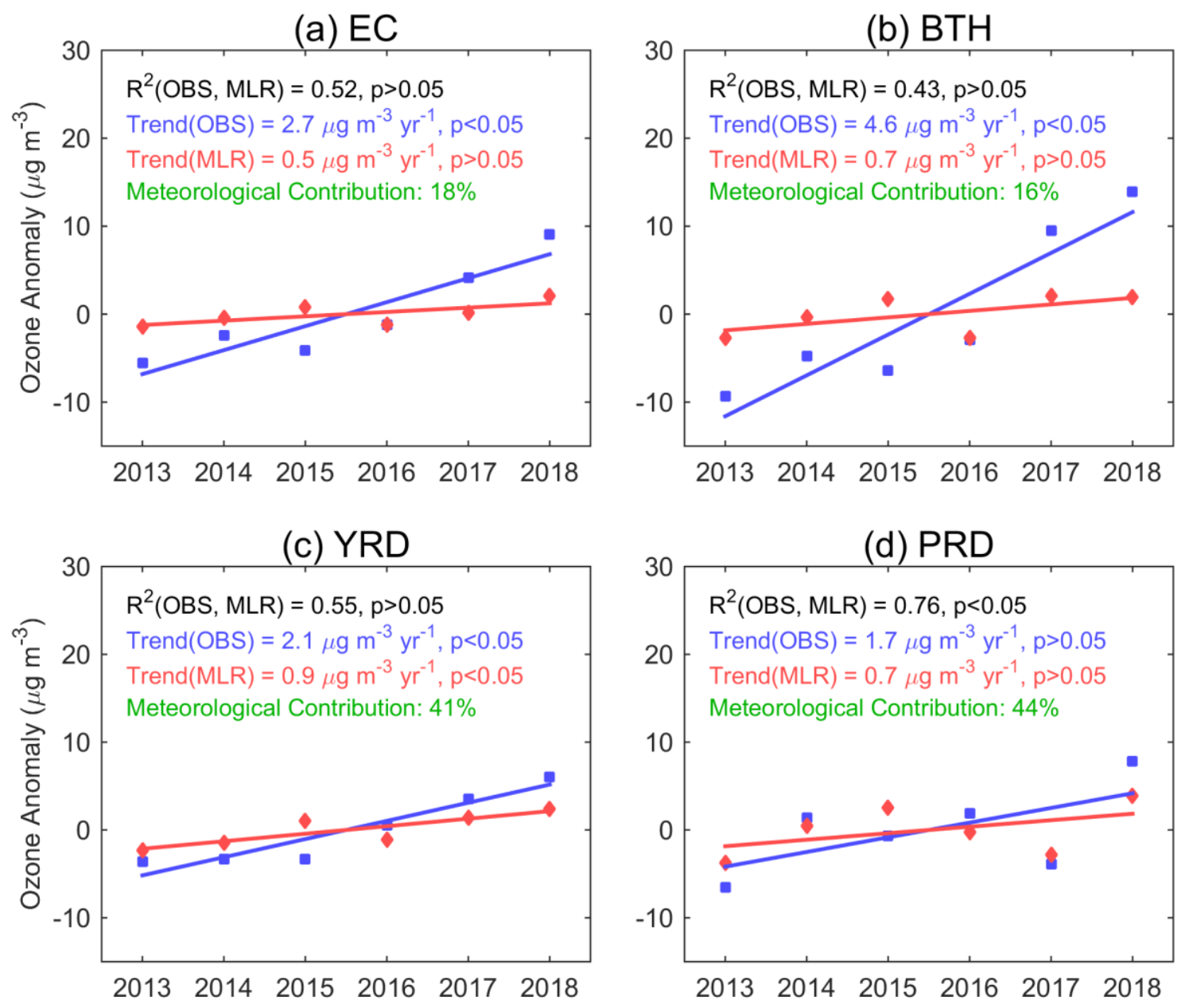

Figure S4. Trends in the regional means of surface ozone from observations (in blue) and cross-validated predictions using MLR (in red) over eastern China (a), BTH (b), YRD (c), and PRD (d) from 2013 to 2018. The coefficient of determination $\left(\mathrm{R}^{2}\right)$ between the observed and predicted ozone is shown in black. The contribution of meteorology described by the MLR to the observed ozone trend is shown in green. 
(a) P1: PSW

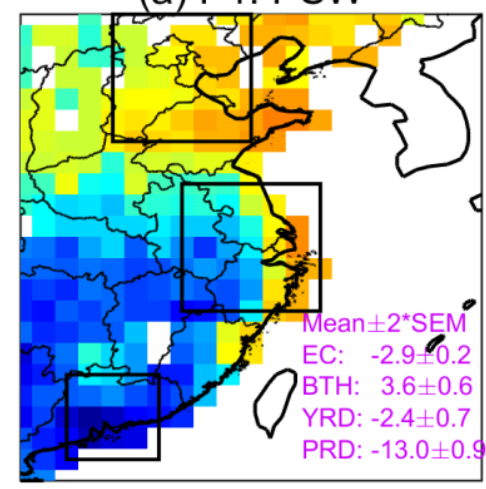

(d) P4: PWC

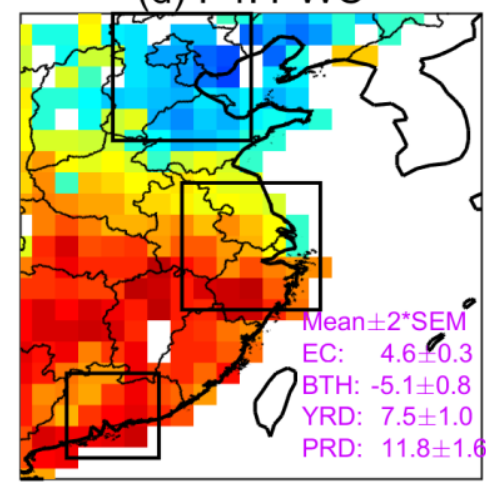

(b) P2: PS

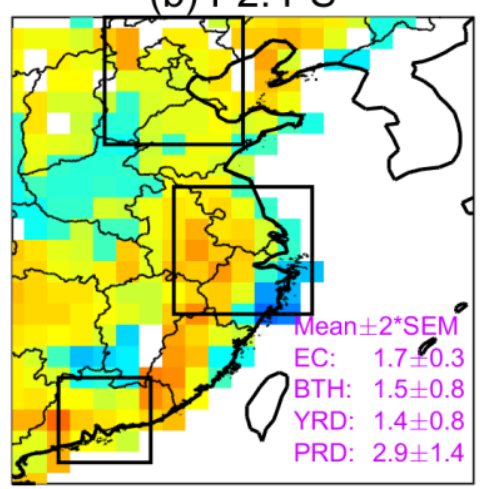

(e) P5: PSWPSH

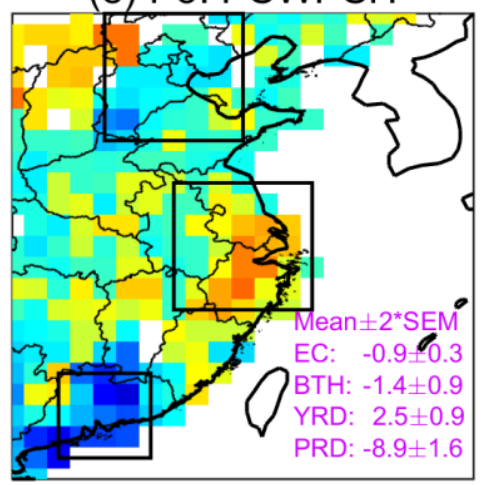

(c) P3: PNECV

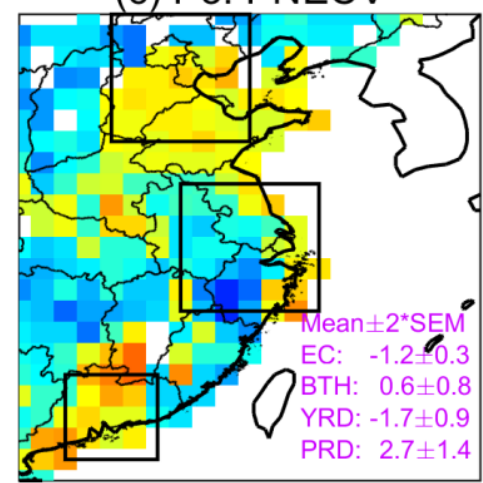

(f) P6: PTC

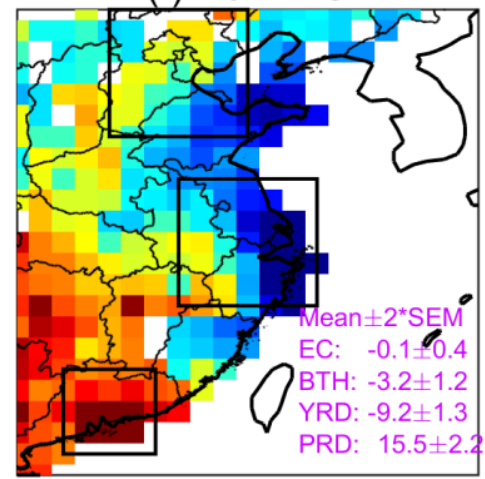

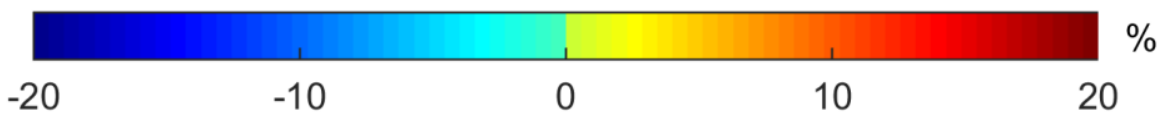

Figure S5. The mean relative anomalies (in \%) of observed daily surface ozone under each of the SWPs during 2013-2018. The regional mean anomalies ( \pm two times of the standard error of the mean) are shown in the bottom right corner of each panel. The boxed areas indicate BTH, YRD, and PRD, respectively, in the north, center, and south of the study domain. 